\title{
NON-LINEAR BEHAVIOUR OF STRUCTURAL WALLS
}

\author{
SALIMA DJEHAICHIA ${ }^{1}$ \& RACHID LASSOUED ${ }^{2}$ \\ ${ }^{1}$ Department of Architecture, Faculty of Science and Technology, University of Jijel, Algeria. \\ ${ }^{2}$ Department of Civil Engineering, Faculty of Science and Technology, Laboratory of Materials and Durability of \\ Constructions (LMDC), University Mentouri Constantine, Algeria.
}

\begin{abstract}
The vulnerability of reinforced concrete structures, which were built in the 1970s, under the effects of an earthquake is one of the major concerns of researchers, because the designs of these structures have been based on regulations, which are no longer valid. The parameters taken into account in this study to idealize the regulatory shortcomings are: low ratio of reinforcement, type of reinforcement and moderate resistance of concrete. The analysis to test these altered structures with one or both of the above parameters is carried out in the non-linear domain from the perspective of analysing their behaviour in an earthquake. In this paper, the modelling strategy is based on finite elements combined with a discretization of the shear wall most stressed by successive thin layers. The estimation of level of performance is achieved using capacity curves under increasing incremental loads; a non-linear characteristic force-displacement relationship can be determined. The results of the numerical model are compared with those of the Algerian seismic code (RPA). Through this comparison, it was found that there is an improvement in terms of displacement, shearing action and ductility. The introduction of confining as a local model makes it possible to refine the numerical model and improve the total behaviour of the structure. A parametric analysis is carried out to highlight the obvious weakness of structures designed and built in the 1970s.
\end{abstract}

Keywords: finite-element method, former structures, modelling, pushover analysis, RPA.

\section{INTRODUCTION}

The Algerian seismic code (RPA-99) allows an acceptable level of safety to be achieved for new structures located in a seismic zone. However, former structures pose an important problem of safety in the case of a violent earthquake, because these structures have been designed according to regulations that are no longer in use. Due to safety concerns, various researchers in the seismic domain have studied - through different models - the estimation of damage to this type of structure. The seismic behaviour of the shear wall has been the subject of several pieces of research, in the theoretical, numerical and experimental domains. For example, the studies of Schnobrich [1], Fintel and Ghosh [2], Agrawal et al. [3], Subiedi [4] and Paulay [5] have demonstrated, in particular, that coupled shear walls with openings may present ductile behaviour in effectively dissipating the energy induced by an earthquake. There have been several studies proposing two big families of modelling for analysing the behaviour of structures' walls. Rigorous modelling by finite elements, based on a detailed interpretation of the local behaviour, has been undertaken by, for example, Spacone et al. [6] and Moulin et al. [7]. Their general principle focuses on the integration of the constraints developed in the fibres of each section. This model permits the resultant of the internal efforts in each section to be calculated. Martinelli and Filippau [8] showed that multifibre modelling is appropriate for representing the hysteretic behaviourof reinforced concrete cross walls. It allows, for example, the gradual change in the neutral axis position of sections as they crack to be taken into account. Belmouden and Elharif [9] have based their study on the modeling of reinforced concrete load-cross walls by multilayer finite elements. The work of Vulcano et al. [10] and Hemsas [11] etc. focuses on a strategy based on the macro-element concept. Each macro-element is composed of $n$ uni-axial sub-elements, assembled in parallel, in addition to a 
non-linear horizontal spring, which represents the shear. The aim of this paper is to present a method capable of evaluating the global behaviour of a structure from the local behaviour of its concrete and reinforcement. Regarding concrete, the research of Mazars [12], the constitutive model of Kent and Park [13] and that of Mander et al. [14] can be quoted. As regards reinforcement behaviour, we have opted for the elasto-plastic model to reduce the time and size of calculations in the modelling. The parameters taken into account in this study to idealize the deficiencies of the regulations are: low ratio of reinforcements, type of reinforcement, and moderate resistance of concrete. The analysis to test these altered structures with one or both of the above parameters is realized in the non-linear domain in order to analyse their behaviour during an earthquake. The section of reinforced concrete can be easily modelled as a stack of several layers of steel and concrete. The multilayer finite element has therefore been selected for this study in order to be able to assess the local damage, combined with a discretization of the most solicited wall by successive thin layers. In this case, we can cite the work of Miao et al. [15], who took a hybrid model combining the macro-elements and local sections in the context of analysing the influence of local behaviour on the overall behaviour of the structure. The capacity curves derived from an analysis of incremental load allow the structure's performance point to be located. The results of the numerical model are compared with those obtained by the Algerian seismic code (RPA), and therefore, it has been found that there is an improvement in terms of displacement, shearing action, and ductility. The introduction of confining as a local model makes it possible to refine the numerical model and improve the total behaviour of the structure. A parametric analysis has been carried out and has been concretized to highlight the obvious weakness of the structures conceived and built in the 1970s.

\section{BEHAVIOUR AND DISCRETIZATION}

\subsection{Concrete model}

Mander et al.'s model [14] allows us to simulate effectively the behaviour of confined and unconfined concrete, ordinary or with high resistance in compression, as in the case of tension. This unified model resulted from the work of research undertaken by the New Zealand school. It is characterized by the simplicity of its application and by its coverage of all forms of all used section shapes; the effective constraint of lateral confining, equal in each direction, was found as a function of the ratio of the compressive strength of the confined concrete $\mathrm{f}_{\mathrm{cc}}$ and the un-confined $\mathrm{f}_{\mathrm{co}}{ }_{\mathrm{co}}$. This model is defined by the following equations (1) and (2):

$$
\begin{gathered}
f_{c}=\frac{f_{c c}^{\prime} m r}{r-1+m^{r}} \text { where } m=\frac{\varepsilon_{c}}{\varepsilon_{c c}} \\
\frac{f_{c c}^{\prime}}{f_{c o}^{\prime}}=2.25 \sqrt{1+7.94 \frac{f_{l}^{\prime}}{f_{c o}^{\prime}}}-2.0 \frac{f_{l}^{\prime}}{f_{c o}^{\prime}}-1.25
\end{gathered}
$$

The transversal passive pressure of the confining ( $\mathrm{f}^{\prime}{ }_{1}=\mathrm{k}_{\mathrm{e}} \mathrm{f}_{1}$ ) deployed by the transversal reinforcement on the core of the concrete, resulting from the triaxial compression state, clearly significantly improves the compressive strength and possibly the ductile behaviour. On the basis of this fact, the ultimate longitudinal strain in compression of the confined concrete will not be reached by failure of the transversal reinforcement. $\mathrm{k}_{\mathrm{e}}$ represents the effective 
coefficient of confining, taking into account the arc effect on the concrete included between the transverse and the longitudinal reinforcements.

\subsection{Steel model}

For reinforcement, the Algerian code of concrete CBA-93 [16] adopts a conventional stressstrain diagram, defined by a deformation at the end of the elastic phase, $\varepsilon_{\mathrm{se}}=\sigma \mathrm{s} / \mathrm{Es}$, and an equal ultimate deformation of $10 \%$.

\subsection{Wall discretization and building description}

The shear wall is modelled using a fine mesh of a smeared multi-layer shell element, based on the principles of composite material mechanics; it can simulate the coupled in-plane/outof-plane bending and the coupled in-plane bending, shear non-linear behaviour of reinforced concrete shear walls. The shell element is made up of many layers of different thicknesses and different material properties, which are assigned to various layers, as shown in Figure 1. This means that the rebars are smeared into one layer or more. During the finite element calculation, the axial strain and curvature of the middle layer can be obtained in one element. Then, according to the assumption that 'plane remains plane', the strains and the curvatures of the other layers can be determined, and the corresponding stress will be calculated through the constitutive relations of the material which is assigned to the layer. The recommendations of ATC 40 [17] and FEMA 356 [18] define the performance criteria for the flexural RC members in terms of plastic rotations.

\section{NUMERICAL EXAMPLE}

Our study focused on a seven-storey reinforced concrete wall building, which has residential occupancy, regular in plane and in elevation, with a typical storey height of $3.06 \mathrm{~m}$ and $4.00 \mathrm{~m}$ for the ground floor. The building is located in the second seismic area (IIb zone) with a local soil profile of S2. The model developed in this study was implemented in Sap 2000 software [19]. The solid slabs fulfil the role of a rigid horizontal diaphragm. The storey mass is formed using an appropriate distribution of the slabs loads, which are composed of self-weight $(G)$ and $20 \%$ of the live load (Q). The design spectrum curve is constructed according to the Algerian seismic code RPA [19], and the different characteristics of the materials are summarized in Table 1. Shear walls are modelled by multilayer shell elements, which are based on finite elements combined with a discretization of the most stressed shear wall. For a non-linear multilayer material shell model, Mander's stress-strain relation [14] is adopted to represent the

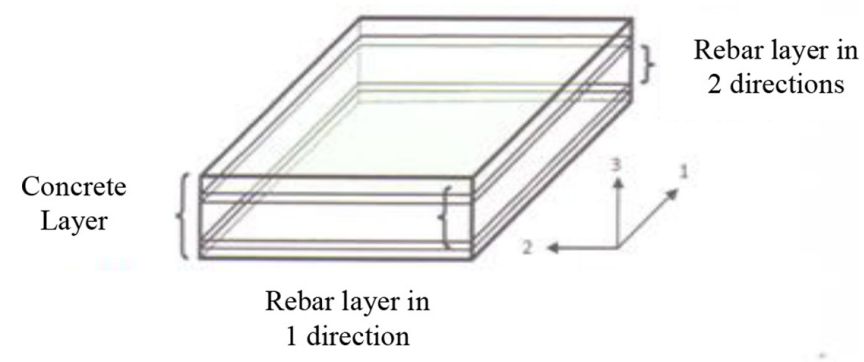

Figure 1. Multilayer shell elements. 
Table 1: Characteristics of materials.

\begin{tabular}{llllll}
\hline & Ref. Case & 1st Case & 2nd Case & 3rd Case & 4th Case \\
\hline fcy & 25 & 12 & 25 & 25 & 12 \\
fy & 400 & 400 & 400 & 215 & 215 \\
$\mathbf{f}_{\text {cc }}$ & 36.73 & 18.98 & 25.87 & 25.67 & 12.86 \\
$\varepsilon_{\text {cu }}(10-3)$ & 67.6 & 62.1 & 28.5 & 35.1 & 7.72 \\
\hline
\end{tabular}

concrete material model; compressive strain at maximum stress is $2 \%$ and ultimate strain is $5 \%$. For reinforcement, the concrete code of Algerian CBA-93 [16] adopts a conventional diagram stress-strain, defined by a deformation at the end of the elastic phase, $\varepsilon_{\mathrm{se}}=\sigma \mathrm{s} / \mathrm{Es}$ and an equal ultimate deformation of $10 \%$ with a constraint in the reinforcement. The reinforcement in both longitudinal and transversal directions is considered as a separate layer. Two layers for each direction are taken into account for upper and lower reinforcements in the cross section.

\subsection{Results and discussion}

The parameters taken in this analysis essentially focussed on the low resistance of concrete (resistance equal to 12 and $16 \mathrm{MPa}$ ). The second case is based on the slightly reinforced structure; the third case is a structure reinforced with smooth bars, and the last case will analyse both of the above-mentioned parameters. To check the resistance of the structure, the evaluation was carried out on the shear action at the base of the structure noted $\mathrm{V}_{\text {base}}$, compared to the one obtained by RPA [20], which is given by the following expression:

$$
\mathrm{V}_{\mathrm{RPA}}=\frac{A \cdot D \cdot Q}{R} W
$$

The values obtained by the capacity curve were provided by pushover analysis. The monitoring of the ductility of some of the structure's preselected critical zones is one of the most important observations made during the non-linear analysis; this is defined by the factor of displacement ductility, $\mathrm{u}_{\mathrm{D}}$, which is often employed in seismic calculations. This factor is also defined as a formula that binds $\delta \mathrm{u}$ (the maximum horizontal displacement of a defined level of the structure) with $\delta \mathrm{y}$ (the displacement corresponding to the yield stress).

$$
\mathrm{u}_{\mathrm{D}}=\frac{\delta \mathrm{U}}{\delta \mathrm{Y}}
$$

On the basis of the capacity curves for each case (Figs. 2-7) and according to the results mentioned in Table 2, we note that when the ratio of $\mathrm{V}_{\text {base }}$ to $\mathrm{V}_{\mathrm{RPA}}\left(\mathrm{V}_{\text {base }} / \mathrm{V}_{\mathrm{RPA}}\right)$ takes a value greater than 1 . This implies that the capacity of the structure conforms with the requirements; we find, in this case, an improvement in resistance, and therefore no risk of collapse is envisaged. However, for the other cases (the slightly reinforced concrete, the resistance of concrete equal to $12 \mathrm{MPa}$ and the reinforcement with smooth bars), it was found that the ratio is lower than 1, meaning that the structure is threatened (there is a danger to the building and to the safety of life). In terms of ductility, we can make the following observations:

- Displacement ductility can be influenced by resistance; concrete of 12 and $16 \mathrm{MPa}$ is a little more ductile than concrete of $25 \mathrm{MPa}$. 


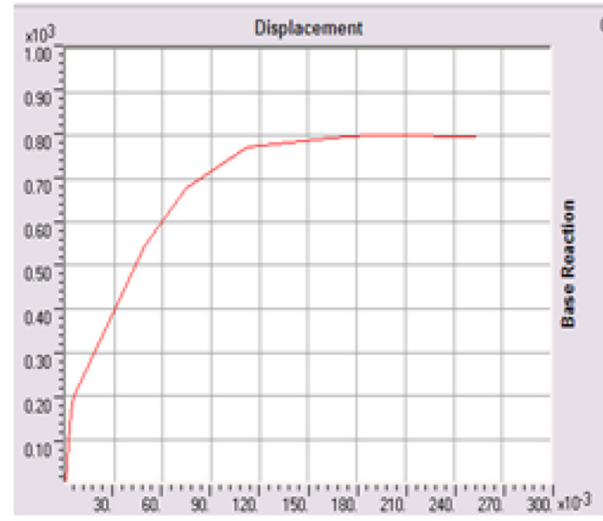

Figure 2: Reference case concrete strength ( $f_{c 28}=25 \mathrm{MPa}$ conform to RPA).

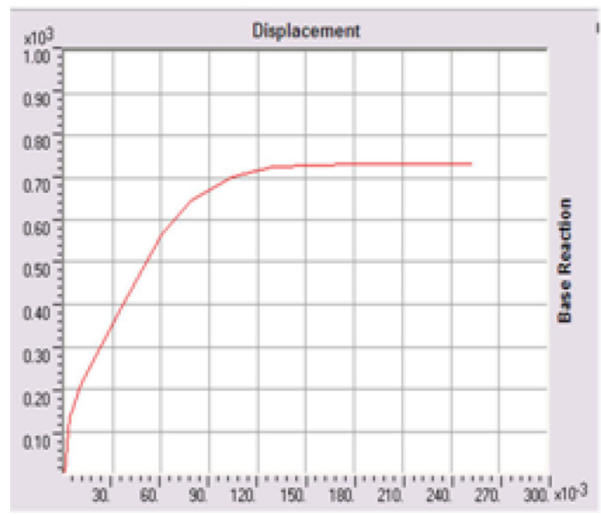

Figure 4: First case $\left(\mathrm{f}_{\mathrm{c} 28}=12 \mathrm{MPa}\right)$.

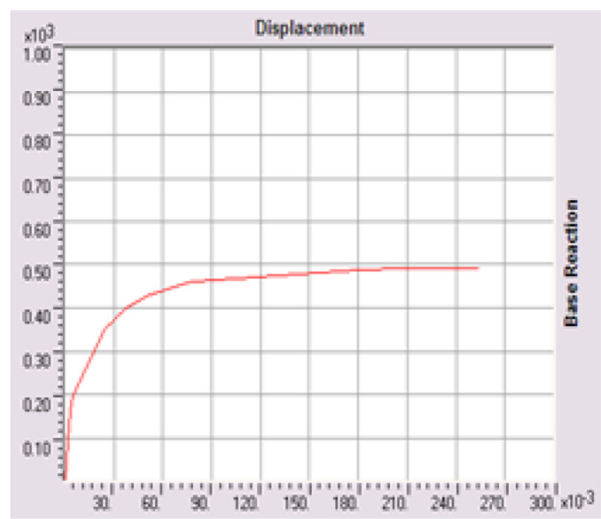

Figure 6: Third case (structure reinforced with smooth bars and $\mathrm{f}_{\mathrm{c} 28}=25$ $\mathrm{MPa}$ )

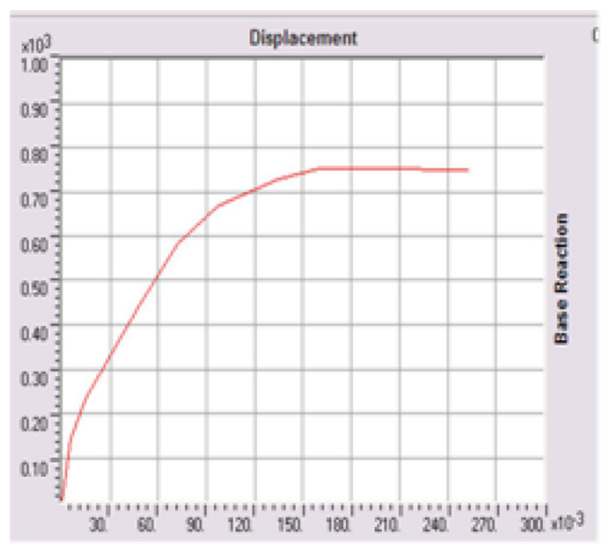

Figure 3: First case $\left(\mathrm{f}_{\mathrm{c} 28}=16 \mathrm{MPa}\right)$.

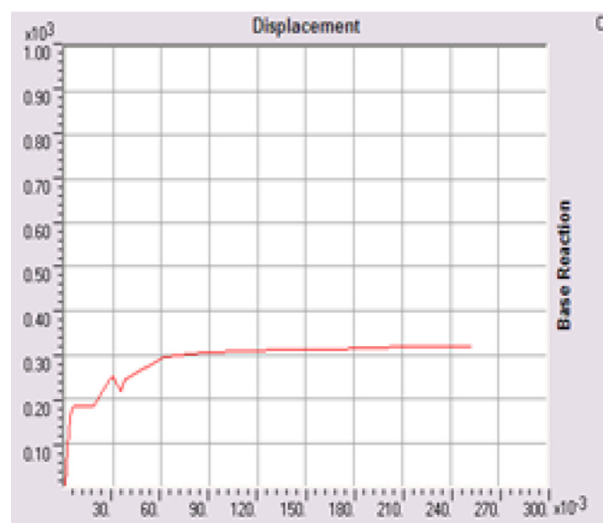

Figure 5: Structure reinforced with slightly reinforced concrete and $\mathrm{f}_{\mathrm{c} 28}=25 \mathrm{MPa}$.

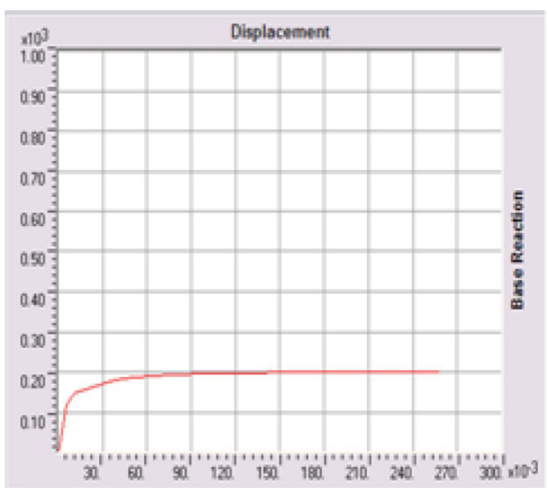

Figure 7: Fourth case (structure reinforced with smooth bars and $\mathrm{f}_{\mathrm{c} 28}=12$ $\mathrm{MPa})$. 
Table 2: Evaluation of the capacity-demand ratio in terms of resistance and ductility.

\begin{tabular}{lll}
\hline & $\mathrm{V}_{\mathrm{BAS}} \mathrm{E} / \mathrm{V}_{\mathrm{RPA}}$ & $\mathrm{uD}$ \\
\hline Reference case (conform to the RPA) & 1.89 & 3.7 \\
Concrete of $16 \mathrm{MPa}$ & 1.78 & 3.03 \\
Concrete of $12 \mathrm{MPa}$ & 1.70 & 2.28 \\
Slightly reinforced concrete & 0.74 & 2.18 \\
Concrete reinforced with smooth bars & 1.14 & 2.96 \\
Concrete with $12 \mathrm{MPa}$ and structure reinforced with & 0.47 & 1.3
\end{tabular}
smooth bars

- According to the comparison between the reference case and the case of concrete reinforced with a minimum section, the behaviour of the structure appears to be affected by the ratio of reinforcement; an increase in this parameter increases the displacement ductility.

- Type of reinforcement: our analysis has highlighted that displacement ductility decreases with the use of smooth bars as reinforcement.

Lightly reinforced structures or those having a low compressive strength of concrete, according to the case analysed, have proved to be vulnerable and must be strengthened.

\section{CONCLUSION}

The main object of this numerical example is to show the non-linear behaviour of lightly reinforced concrete structural walls in a seismic zone; consequently, we can issue the following conclusions:

The post-elastic characteristics of the materials have a preponderant influence on the behaviour of the structural elements in the plastic domain.

- Sufficient multilayer fine modelling can allow a cartography, which reflects the state of stress on any point of the wall.

- The calculation in the non-linear domain has permitted various improvements in terms of displacement, resistance and ductility.

The structures realized in the 1970s proved to be vulnerable due to the use of a low compressive strength of concrete or a small amount of reinforcement, and they must be strengthened.

\section{REFERENCES}

[1] Schnobrich, W.C., Behaviour of RC structures predicted by finite element method. Computers and Structures, 7(3), pp. 365-376, 1977. https://doi.org/10.1016/0045-7949(77)90074-8.

[2] Fintel, M. \& Ghosh, S.K., Application of inelastic response history analysis in the aseismic design of a 31-storey frame-wall building. Earthquake Engineering and Structural Dynamics, 2, pp. 325-342, 1974. 
[3] Agrawal, A.B., Jaeger, L.G. \& Mufti, A.A., Response of RC shear wall underground motions. American Society of Civil Engineers Journal of Structural Division, 107, pp. 395-411, 1981.

[4] Subeidi, N.K., RC coupled shear wall structures. 11. Ultimate strength calculations. American Society of Civil Engineers Journal of Structural Engineering, 117(3), pp. 681-698, 1991.

https://doi.org/10.1061/(asce)0733-9445(1991)117:3(681)

[5] Paulay, T., The design of ductile RIC structural walls for earthquake resistance. Earthquake Spectra. The Professional Journal of the Earthquake Engineering Research Institute, 2(4), 783-823, 1986.

https://doi.org/10.1193/1.1585411

[6] Spacone, E., Filippou, F.C. \& Taucer, F.F., Fibre beam-column model for the nonlinear analysis of r/c frames: Part I, formulation. Earthquake Engineering and Structural Dynamics, 25(7), 711-725, 1996.

https://doi.org/10.1002/(sici)1096-9845(199607)25:7<711::aid-eqe576>3.0.co;2-9

[7] Moulin, S., Davenne, L. \& Gatuingt, F., Eléments de poutre multifibre, Documentation du Code_Aster, Manuel de Référence R3.08.08, 2003. Available at: http:// www.code-aster.org (accessed 06 October 2006).

[8] Martinelli, P. \& Filippou, F.C., Simulation of the shaking table test of a seven-story shear wall building. Earthquake Engineering and Structural Dynamics, 38(5), pp. 587607, 2009.

https://doi.org/10.1002/eqe.897

[9] Belmouden, Y. \& Elharif, A., Modélisation des murs porteurs en béton armé par éléments finis multicouches. Revue Européenne des Eléments finis (REEF), 12, pp. 907-932, 2003. (Editions Lavoisier, Août.)

[10] Vulcano, A., Bertero, V.V. \& Coloti, V., Analytical modeling of RC structural walls. Proceedings, 9th World Conference on Earthquake Engineering 6, Tokyo-Kyoto, 1988.

[11] Hemsas, M., Modélisation par macro-éléments du comportement non-linéaire des ouvrages à voiles porteurs en béton armé, Thèse de doctorat, Université de Bordeaux, France, 2011.

[12] Mazars, J., Application de la mécanique de l'endommagement au comportement non linéaire et à la rupture du béton de structure. Thèse de doctorat d'État, Université Paris, France VI, 1984.

[13] Kent, D.C. \& Park, R., Flexural member with confined concrete. Journal of Structural Division, Proceedings of the American Society of Civil Engineers, 97(7), pp. 19691990, 1971.

[14] Mander, J.B., Priestley, M.J.N. \& Park, R., Theoretical stress-strain model for confined concrete. Journal of Structural Engineering, 114(8), pp. 1804-1825, 1988. https://doi.org/10.1061/(asce)0733-9445(1988)114:8(1804)

[15] Miao, Z.W., Lu, X.Z., Jiang, J.J. \& Ye, L.P., Nonlinear FE Model for RC shear walls based on multi-layer shell element and microplaneconstitutive model. Computational Methods in Engineering and Science, EPMESC X, Sanya, Hainan,China, 2006. https://doi.org/10.1007/978-3-540-48260-4_50

[16] CBA-93., Algerian concrete Code 1993. Technical rules document DTR-BC National Center of Applied Research in Paraseismic Genius (CGS), Algiers, 1994. 
[17] Applied Technology Council 1996. ATC-40-Seismic Evaluation and Retrofit of Concrete Buildings, Redwood City, California, 1996.

[18] FEMA 356. Pre-standard and Commentary for the Seismic Rehabilitation of Buildings, American Society of Civil Engineers, Reston, Virginia, 2000.

[19] CSI2009. SAP2000. Static and Dynamic Finite Element Analysis of Structures 14.0, Computers and Structures, Inc., Berkeley, California, 2000.

[20] PA99. Algerian Paraseismic rules, Version 2003, regular technical document, DTR B C 2 48, Paraseismic National Center of Applied Research Engineering, Algiers, 2003. 